\title{
A ÁGUA EM JOGO: UM RECURSO DIGITAL PARA ENSINAR E APRENDER ${ }^{1}$
}

\author{
THE WATER IN PLAY: A DIGITAL RESOURCE TO TEACH AND LEARN \\ Sandra Cadore Peixoto ${ }^{2}$, Cristiano Rodrigo Bohn Rhoden ${ }^{3}$ e \\ Thais Scotti do Canto-Dorow ${ }^{4}$
}

\section{RESUMO}

A destruição crescente dos recursos naturais em nosso Planeta tem exigido ações para incentivar o interesse e a responsabilidade dos estudantes acerca de problemas ambientais, em especial, sobre a importância da conservação de um bem precioso para o ser humano, que é a Água. Entre essas ações está a utilização de recursos didáticos, em âmbito educacional, destacando-se os jogos, simuladores, editores de texto, ferramentas de apresentação multimídia, entre outros. Este artigo apresenta uma iniciativa de docentes e discentes do curso de pós-graduação em Ensino de Ciências e Matemática e do curso de graduação em Engenharia Química, da Universidade Franciscana, e teve como objetivo construir e aplicar um jogo digital, denominado "Acqua", visando sensibilizar estudantes da educação básica sobre a importância de conhecer sobre a água e sobre a preservação desse recurso. Para construção do jogo "Acqua" digital foi utilizado o aplicativo Kahoot, um serviço gratuito para PC. O jogo está integrado por dez perguntas de múltipla escolha, que devem ser respondidas em determinado tempo. Para ser testado, o link foi enviado para 13 participantes, na faixa etária de 6 a 10 anos. Por meio do relatório emitido pela plataforma Kahoot, foi possível verificar a classificação de cada jogador, a porcentagem das respostas corretas, questões sem resposta e a pontuação final. Os resultados também mostraram que nenhum dos jogadores obteve um score de 100\% de acertos. A partir dessas informações observou-se as potencialidades e as fragilidades de cada jogador, relacionadas ao foco deste estudo, sinalizando situações, sobre o tema, que devem ser abordadas no ensino com mais profundidade.

Palavras-chave: Ensino, Engenharia, Conservação da água.

\section{ABSTRACT}

The increasing destruction of the natural resources on our planet require actions to encourage students regarding environmental problems, in particular, on the importance of water conservancy. Among these actions, relay the use of didactic resources, in the educational scope, especially games, simulators, text editors, multimedia presentation tools, among others. This article presents an initiative by professors and students of the Master Course in Teaching of Science and Mathematics and the graduation in Chemical Engineering the Franciscan University, and aimed to build and apply a digital game, called "Acqua", aiming to sensitize the players about the importance of water and the preservition of this resource. The Kahoot platform, a free service for PC, was used to build the digital game "Acqua". The game consists of ten Multiple choice questions, which must be answered in a certain time. To be tested, the link was sent to 13 participants, aged 4 to 10 years. Through the asnwers by the Kahoot platform, it was possible to check the rating of each player, the percentage of correct answers, unanswered questions and the final score. Based on this information, the strengths and weaknesses of

\footnotetext{
${ }^{1}$ Trabalho de Iniciação Científica - Projeto de extensão

${ }^{2}$ Docente do Curso de Engenharia Química e do Programa de Pós-graduação em Ensino de Ciências e Matemática Universidade Franciscana - UFN. E-mail: sandracadore@ufn. edu.br

${ }^{3}$ Docente do Curso de Engenharia Química - Universidade Franciscana - UFN. E-mail: cristianorbr@gmail.com

${ }^{4}$ Docente do Curso de Biomedicina e do Programa de Pós-graduação em Ensino de Ciências e Matemática - Universidade Franciscana - UFN. E-mail: thaisdorow@gmail.com
} 
each player were observed, related to the focus of this study, signaling situations on the theme, which should be addressed in more intensive teaching.

Keywords: Teaching, Engineering, Water conservancy.

\section{INTRODUÇÃO}

A água potável é aquela própria para o consumo, que contém certa quantidade de sais minerais dissolvidos, importantes para a saúde, e deve estar livre de materiais tóxicos e micro-organismos patogênicos, como bactérias, protozoários, entre outros. A água é de fundamental importância para a vida de todas as espécies. No entanto, um problema enfrentado com esse recurso está relacionado à sua degradação, ou seja, a água vem sendo poluída de tal maneira, que nenhuma água pode ser distribuída/consumida sem ao menos realizar um processo de desinfecção.

A poluição dos recursos hídricos tem exigido ações para incentivar o interesse e a responsabilidade da comunidade acerca de problemas ambientais, em especial, sobre a importância da conservação de um bem precioso para o ser humano, que é a água. Entre essas ações está a utilização de recursos didáticos, em âmbito educacional, destacando-se os jogos, simuladores, editores de texto, ferramentas de apresentação multimídia, entre outros. Os jogos, para fins educacionais, devem ter seu objetivo bem definido para o sucesso da aprendizagem, oferecendo auxílio ao conteúdo das disciplinas a serem trabalhadas e, ainda, desenvolvendo habilidades que ampliem nos alunos a capacidade intelectual e cognitiva. No processo de ensino e aprendizagem, diferentes propostas didáticas podem ser apresentadas a fim de manter e despertar atitudes críticas, criativas e científicas em todas as áreas do conhecimento, em especial, na Educação Ambiental. Nesse sentido, ações inovadoras são necessárias para incentivar o interesse e a responsabilidade dos estudantes acerca de problemas ambientais, em especial, aqui, sobre a importância da conservação de um bem essencial para o ser humano, que é a água.

Os jogos são atividades lúdicas estruturadas por meio de estratégias que permitem ensinar um conteúdo ou, simplesmente, ensinar a jogar. Os jogos, no ambiente escolar, tornam a aprendizagem mais atrativa e desafiadora, trazendo benefícios não somente aos alunos como também aos professores, que podem utilizar desse recurso como forma de diversão e aprendizado, transformando simples assuntos do dia a dia em grande conhecimento de forma prazerosa, explorando a imaginação e a criatividade de seus jogadores (PARREIRA et al., 2016).

De acordo com Melo (2005), vários estudos a respeito de atividades lúdicas têm comprovado que o jogo, além de fonte de prazer e descoberta para o aluno, é a tradução do contexto social, cultural e histórico refletido na cultura, podendo contribuir significativamente para o processo de construção do conhecimento como mediador da aprendizagem.

O jogo didático consegue atingir vários objetivos, relacionados às funções cognitivas (processos ligados ao desenvolvimento da inteligência e da personalidade, os quais são fundamentais à construção 
de conhecimento), tais como: afeição (atua no sentido de estreitar os laços de amizade entre os alunos), socialização (melhora sua vida em grupo seja dentro ou fora da escola), motivação (aumenta o interesse por determinados assuntos e estimula a curiosidade) e criatividade (MIRANDA, 2001).

De acordo com as informações transmitidas através da interface do jogo, estabelece-se uma via de comunicação com o jogador, sendo possível compartilhar estas informações de modo a construir "conhecimento" (AGUILERA; MÉNDIZ, 2003).

Nesse contexto, este trabalho teve por objetivo desenvolver e aplicar um jogo pedagógico, denominado de Acqua, visando sensibilizar os jogadores sobre a importância de conhecer a água e de preservar esse recurso.

\title{
REFERENCIAL
}

\section{Qualidade e potabilidade da água}

A água potável é aquela própria para o consumo, que contém certa quantidade de sais minerais dissolvidos, importantes para a saúde, e deve estar livre de materiais tóxicos e micro-organismos patogênicos, como bactérias, protozoários, entre outros. A água é de fundamental importância para a vida de todas as espécies. No entanto, um problema enfrentado com esse recurso está relacionado a sua degradação, ou seja, a água vem sendo gradativamente poluída de tal maneira, que futuramente tornará impossível o seu consumo sem tratamentos altamente específicos. Tundisi et al. (2014, p. 40) citam algumas causas dessa degradação no Brasil:

\begin{abstract}
A ausência do saneamento básico e a falta de tratamento de esgotos de origem doméstica, além da poluição industrial, interferem nos ciclos naturais de rios, lagos e represas. $\mathrm{O}$ desmatamento aumenta a erosão e a sedimentação, diminuindo o volume de água disponível em rios, lagos e represas, interrompe e modifica ciclos biogeoquímicos naturais, altera a sucessão das comunidades terrestres e aquáticas e acelera o transporte de substâncias e elementos tóxicos para os sistemas aquáticos, aumentando a vulnerabilidade destes devido à degradação da qualidade da água.
\end{abstract}

A água é usada para diversos fins, consumo humano, lazer, irrigação, entre outros. A água cristalina, sem gosto e inodora não indica que é apropriada para o consumo humano. As contaminações por vírus, por bactérias e substâncias tóxicas também podem prejudicar a saúde humana. Dessa forma, além de não ter sabor, cheiro e cor, as águas consumíveis devem estar enquadradas em parâmetros mais específicos de qualidade, que são determinados pelo Ministério da Saúde.

O Ministério da Saúde brasileiro define procedimentos de controle e de vigilância da qualidade da água para consumo humano e seu padrão de potabilidade, eliminando possíveis riscos à saúde da população (BRASIL, 2004). 
A Resolução $n^{\circ} 357$ do Conselho Nacional do Meio Ambiente (BRASIL, 2005) “dispõe sobre a classificação dos corpos de água e diretrizes ambientais para o seu enquadramento, bem como estabelece as condições e padrões de lançamento de efluentes, e dá outras providências", está relacionada à qualidade dos recursos hídricos superficiais. Ou seja, utilizam-se parâmetros físicos, químicos e biológicos para enquadrar em uma classe de qualidade e relacionar com os usos preponderantes, uma vez que determinadas águas superficiais, se enquadradas em classe IV (CONAMA 357/2005) não podem ser destinadas ao consumo humano. As águas tratadas são normalizadas conforme a Portaria n 2914/2011 do Ministério da Saúde (BRASIL, 2011). Essa portaria "dispõe sobre os procedimentos de controle e de vigilância da qualidade da água para consumo humano e seu padrão de potabilidade". A Portaria de Consolidação $N^{0}$ 5, de 28 de setembro de 2017, consolida as normas sobre as ações e os serviços de saúde do Sistema Único de Saúde, sendo que o anexo XX dispõe sobre o controle e vigilância da qualidade da água para consumo humano e seu padrão de potabilidade.

\section{Jogos no contexto escolar: um olhar na Base Nacional Comum Curricular}

A Base Nacional Comum Curricular (BNCC) é um documento completo e contemporâneo, que corresponde às demandas do estudante desta época, preparando-o para o futuro. Segundo a BNCC (BRASIL, 2017) a aprendizagem de qualidade é uma meta que o País deve perseguir incansavelmente, e uma das competências gerais da BNCC contempla o compreender, utilizar e criar tecnologias digitais de informação e comunicação de forma crítica, significativa, reflexiva e ética nas diversas práticas sociais (incluindo as escolares) para se comunicar, acessar e disseminar informações, produzir conhecimentos, resolver problemas e exercer protagonismo e autoria na vida pessoal e coletiva.

A BNCC do Ensino Fundamental - Anos Iniciais, ao valorizar as situações lúdicas de aprendizagem, aponta para a necessária articulação com as experiências vivenciadas na Educação Infantil. Tal articulação precisa prever tanto a progressiva sistematização dessas experiências quanto o desenvolvimento, pelos alunos, de novas formas de relação com o mundo, novas possibilidades de ler e formular hipóteses sobre os fenômenos, de testá-las, de refutá-las, de elaborar conclusões, em uma atitude ativa na construção de conhecimentos.

$\mathrm{Na} \mathrm{BNCC}$, o Ensino Fundamental está organizado em cinco áreas do conhecimento, que considera tanto as características do alunado quanto as especificidades e demandas pedagógicas dessas fases da escolarização que se intersectam na formação dos alunos, embora se preservem as especificidades e os saberes próprios construídos e sistematizados nos diversos componentes.

A área Ciências da Natureza, que contempla o componente curricular ciências, por meio de um olhar articulado de diversos campos do saber, precisa assegurar aos alunos do Ensino Fundamental o acesso à diversidade de conhecimentos científicos produzidos ao longo da história, bem como a aproximação gradativa aos principais processos, práticas e procedimentos da investigação científica. 
Para orientar a elaboração dos currículos de Ciências, as aprendizagens essenciais a ser asseguradas neste componente curricular foram organizadas em três unidades temáticas que se repetem ao longo de todo o Ensino Fundamental: Matéria e energia, Vida e evolução e Terra e universo (BRASIL, 2017).

A BNCC e os currículos têm papéis complementares para assegurar as aprendizagens essenciais definidas para cada etapa da Educação Básica, uma vez que tais aprendizagens só se materializam mediante o conjunto de decisões que caracterizam o currículo em ação. Entre outras ações, estabelece a de selecionar, produzir, aplicar e avaliar recursos didáticos e tecnológicos para apoiar o processo de ensinar e aprender.

A BNCC indica que as decisões pedagógicas devem estar orientadas para o desenvolvimento de competências. Por meio da indicação clara do que os alunos devem "saber" (considerando a constituição de conhecimentos, habilidades, atitudes e valores) e, sobretudo, do que devem "saber fazer" (considerando a mobilização desses conhecimentos, habilidades, atitudes e valores para resolver demandas complexas da vida cotidiana, do pleno exercício da cidadania e do mundo do trabalho), a explicitação das competências oferece referências para o fortalecimento de ações que assegurem as aprendizagens essenciais definidas na BNCC (BRASIL, 2017, p. 13).

Nesse sentido, entre muitos recursos didáticos citados no referido documento, os jogos são indicados para auxiliar no desenvolvimento das competências e para promover a aprendizagem em todos os níveis da educação básica.

\section{METODOLOGIA}

O relato deste artigo está ancorado em um projeto de extensão que foi desenvolvido por docentes e discentes do curso de pós-graduação em Ensino de Ciências e Matemática (PPGECIMAT) e do curso de graduação em Engenharia Química da Universidade Franciscana.

Este trabalho foi desenvolvido seguindo as etapas apresentadas no Quadro 1.

Quadro 1- Etapas e atividades desenvolvidas no projeto.

\begin{tabular}{cc}
\hline Etapa & \multicolumn{1}{c}{ Atividade } \\
\hline $1^{\text {a }}$ etapa & Produção do jogo digital ACQUA \\
\hline $2^{\text {a } \text { etapa }}$ & Aplicação do jogo \\
$3^{\text {a } \text { etapa }}$ & Verificação do impacto do jogo \\
\hline \multicolumn{2}{c}{ Fonte: Construção dos autores. }
\end{tabular}

\section{$1^{a}$ etapa: Produção do jogo digital ACQUA}

Para construção do jogo "Acqua” digital foi utilizado o aplicativo Kahoot, um serviço gratuito para PC, que permite o estudante conhecer e aprender a partir de testes de pergunta e resposta que valem pontos, o que também é lúdico. 
O jogo ACQUA é um jogo no formato digital, constituído de onze questões, sendo seis questões de verdadeiro e falso e, cinco na forma de quiz, com 4 alternativas. Além do PC, os participantes podem usar o celular para jogar.

\section{$2^{a}$ etapa: Aplicação do jogo}

Considerando a pandemia causada pelo coronavírus, SARS-CoV-2, a aplicação do jogo ACQUA foi realizada com 13 participantes na faixa etária de 6 a 10 anos, selecionados aleatoriamente, que receberam o link do jogo seguindo as recomendações de isolamento e prevenção da disseminação da doença. Vale ressaltar que todos os participantes da pesquisa foram do sexo feminino, e matriculados no Ensino Fundamental de uma Escola Estadual do município de São Luiz Gonzaga, RS.

\section{$3^{\text {a }}$ etapa: Verificação do impacto do jogo}

Por meio da pontuação, dos acertos e erros de cada questão, pode-se verificar as fragilidades e as potencialidades de cada participante, relacionadas ao foco deste estudo.

\section{RESULTADOS E DISCUSSÕES}

O jogo "Acqua" digital, construído por meio do aplicativo Kahoot, foi disponibilizado no link https://bit.ly/2JHVmHw. A Figura 1 exemplifica questões do jogo, no tipo quiz e verdadeiro e falso.

Figura 1 - Imagem da primeira questão do jogo, no tipo de quiz.

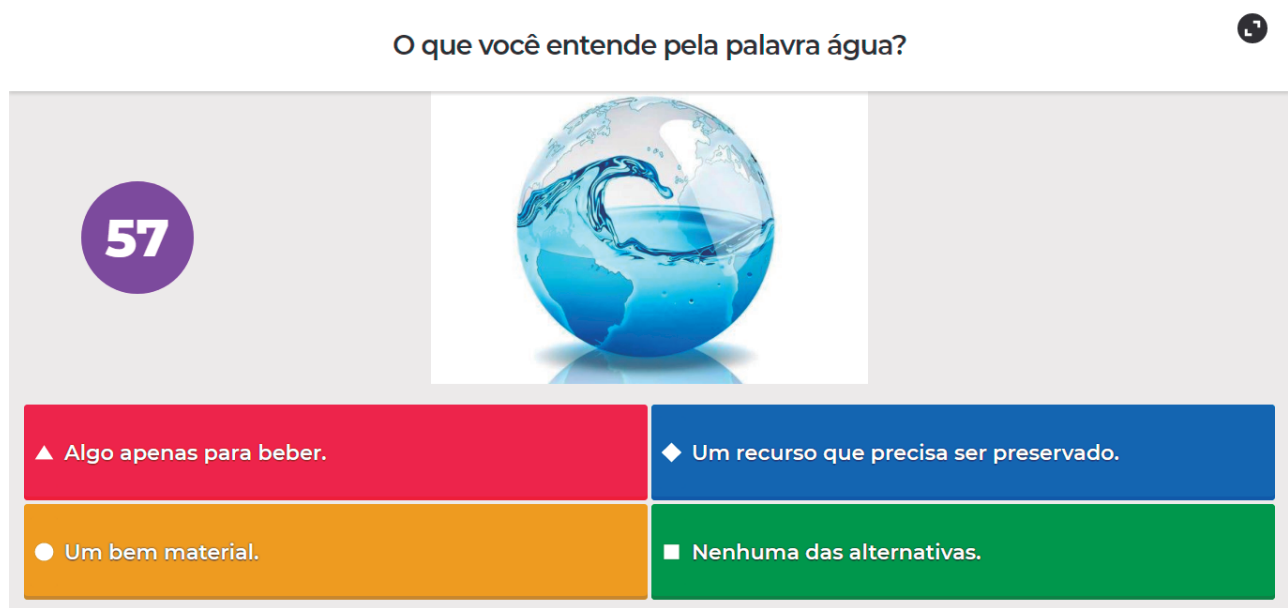


Aágua potável é toda a água própria para o consumo humano. Esta frase é verdadeira ou falsa?

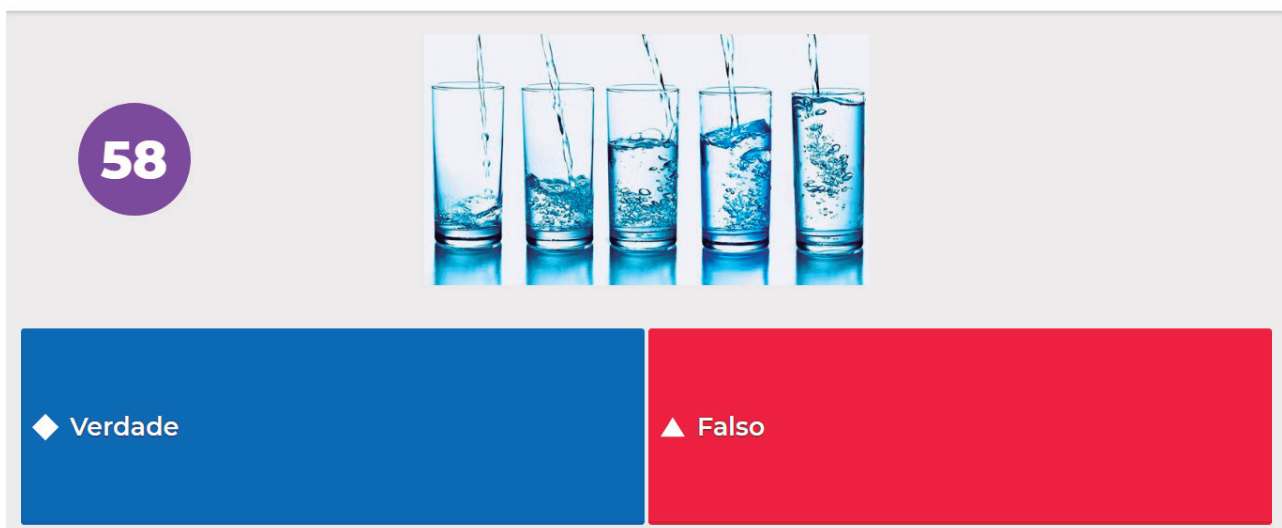

Fonte: Construção dos autores.

O Quadro 2 apresenta os passos percorridos pelo jogador utilizando o jogo ACQUA no celular.

Quadro 2 - Etapas para o participante jogar o jogo ACQUA.

\begin{tabular}{cl}
\hline Etapa & Descrição \\
\hline $1^{\text {a }}$ & Clicar no link do jogo on line. \\
\hline $2^{\text {a }}$ & Preencher o nome em enter nickname. \\
\hline $3^{\text {a }}$ & Clicar em OK, go! \\
\hline $4^{\text {a }}$ & O jogo será iniciado. \\
\hline $5^{\text {a }}$ & Cada pergunta terá um tempo para responder. \\
\hline $6^{\text {a }}$ & Quando a pergunta for para escolher uma das alternativas corretas, aparecerá quiz, nesse caso você \\
& deve clicar na alternativa que considerar correta. \\
& Quando a pergunta for com alternativa verdadeiro ou falso, aparecerá verdadeiro ou falso, nesse caso \\
& clicar em verdadeiro se você considerar a resposta verdadeira, e em falso se considerar falsa. \\
\hline $8^{\text {a }}$ & Se a resposta marcada for correta, aparecerá correto. \\
\hline $9^{\text {a }}$ & Se a resposta marcada for incorreta, aparecerá incorreto. \\
\hline $10^{\mathrm{a}}$ & Clicar em próximo para seguir o jogo. \\
\hline
\end{tabular}

Fonte: Construção dos autores.

$\mathrm{Na} 9^{\text {a }}$ etapa, se a resposta marcada for incorreta, aparecerá incorreto, pois a plataforma nomeia desta maneira quando as questões estão equivocadas. Considerando a contribuição do jogo no processo de ensino e aprendizagem, nesse caso pode-se instigar uma discussão posterior com os participantes, a fim de evidenciar maneiras de minimizar o número que questões incorretas.

Por meio do relatório emitido pela plataforma Kahoot, pode-se observar o nome (apelido) de cada jogador, a classificação, a porcentagem das respostas corretas, o número de questões sem resposta e a pontuação final.

Com estas informações verificou-se as potencialidades e as fragilidades de cada jogador, relacionadas ao foco deste estudo. Cada participante tem uma percepção, porém o interesse em aprender jogando foi observado em todos os participantes.

A Figura 1 demonstra o número de respostas corretas dos participantes da pesquisa. 
Figura 1 - Respostas corretas dos participantes no jogo ACQUA.

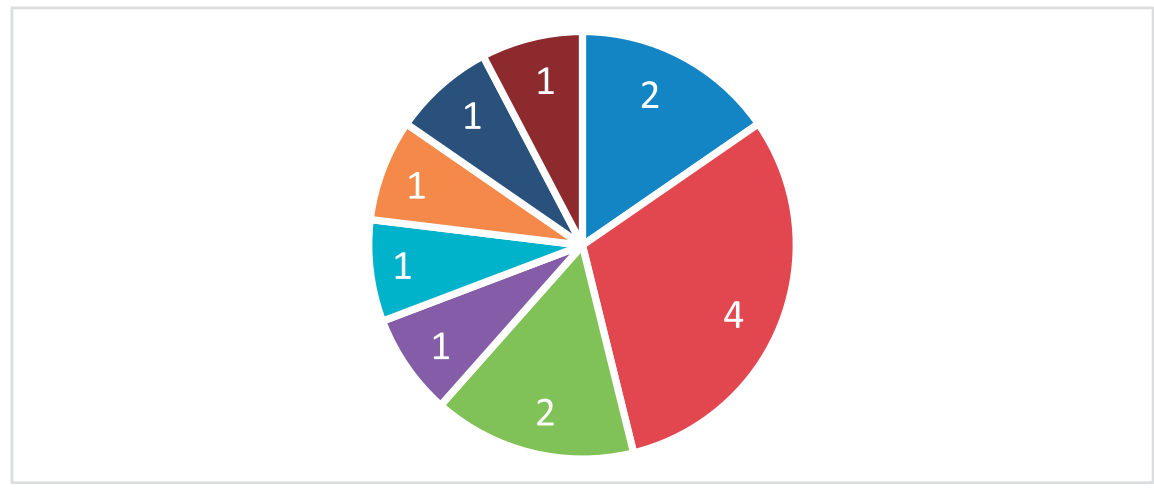

Fonte: Construção dos autores.

Desta forma, a figura 1 ilustra uma relação dentre porcentagem de acertos no jogo, sendo que 2 participantes acertaram 100\% das questões, 4 participantes acertaram 91\%, 2 acertaram 82\%, 1 acertou 73\%, 1 acertou 64\%, 1 participante acertou 55\%, 1 teve 45\% de acertos e 1 participante acertou $18 \%$ das questões.

A Tabela 1 apresenta os acertos dos participantes da pesquisa, em cada questão do jogo ACQUA

Tabela 1 - Porcentagem de acertos em cada questão do jogo ACQUA.

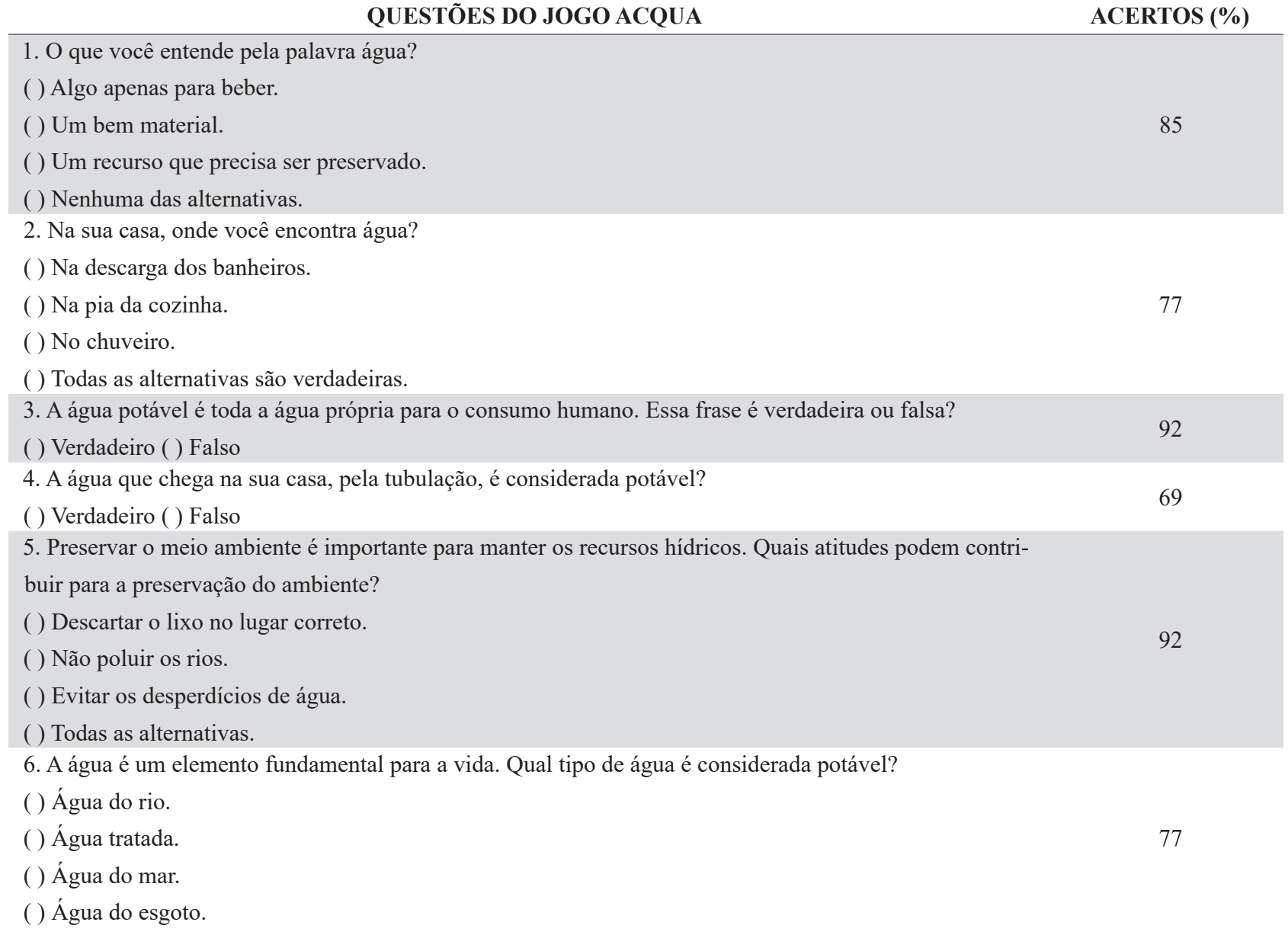




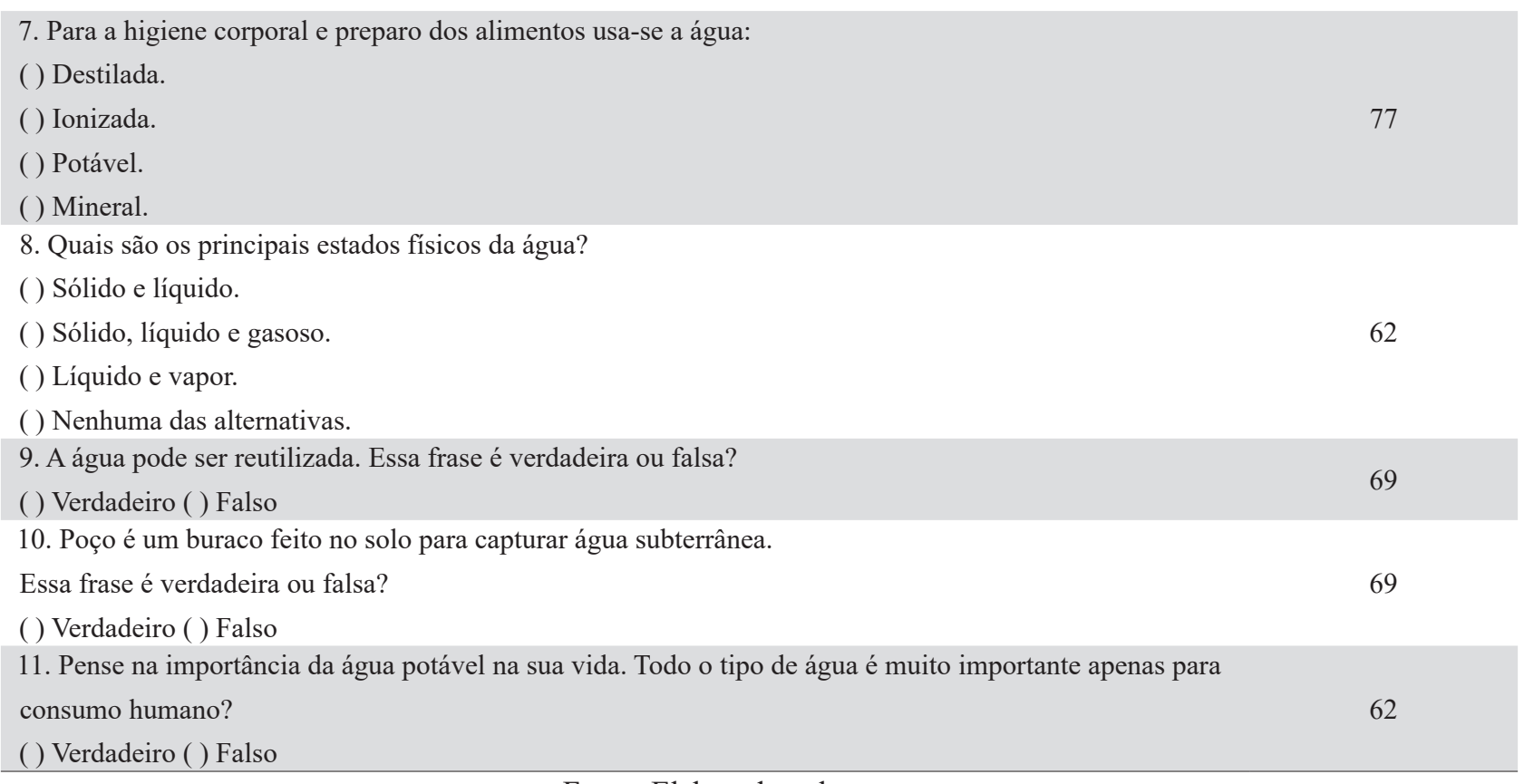

Fonte: Elaborado pelos autores.

\section{CONCLUSÕES E PERSPECTIVAS}

Pode-se concluir que o jogo Acqua mostrou-se ser uma ótima ferramenta para sensibilizar os participantes em relação ao tema conservação da água. Além disso, a colaboração dos estudantes para a produção do jogo digital, permitiu o estímulo dos demais estudantes do curso de Engenharia voltado à sensibilização para problemas sociais.

Os resultados mostraram que nenhum dos jogadores obteve um score de $100 \%$ de acertos, o que nos leva a refletir que, por mais discutida que seja a questão "conservação de água", no cotidiano, ainda assim, permanece uma fração considerável de desconhecimento do tema na referida faixa etária. Desta forma, futuramente, quando da aplicação continuada do jogo entre outros estudantes, os erros devem ser retomados e discutidos, levando ao esclarecimento. Não obstante, o jogo foi elogiado pela totalidade dos participantes, que afirmaram ter reforçado seu aprendizado de forma agradável e descontraída. Verificou-se que a aplicação do jogo Acqua pode ser indicada não somente nas áreas de Ciências e Química, mas também pode e deve ser utilizada para abordar o processo de Educação Ambiental nos ambientes de ensino formal e não formal.

\section{REFERÊNCIAS}

AGUILERA, M.; MÉNDIZ, A. Video games and education (Education in the face of a "Parallel School"). ACM Computers in Entertainment, v. 1, n. 1, 2003. Disponível em: https://bit.ly/37Dw5X4. Acesso em: 17 ago. 2020. 
BRASIL. Ministério da Educação. Base Nacional Comum Curricular. 2017. Disponível em: http://basenacionalcomum.mec.gov.br. Acesso em: 20 de jul. 2020.

BRASIL. Ministério do Meio Ambiente. Resolução CONAMA n 357, de 17 de março de 2005. Dispõe sobre a classificação dos corpos de água e diretrizes ambientais para o seu enquadramento, bem como estabelece as condições e padrões de lançamento de efluentes, e dá outras providências. Diário Oficial da União, Brasília, DF, 18 mar. 2005. p. 58-63.

BRASIL. Ministério da Saúde. Portaria No 518, de 25 de março de 2004. Estabelece os procedimentos e responsabilidades relativos ao controle e vigilância da qualidade da água para consumo humano e seu padrão de potabilidade, e dá outras providências.

BRASIL. Ministério da Saúde. Portaria n 2.914, de 12 de dezembro de 2011. Dispõe sobre os procedimentos de controle e de vigilância da qualidade da água para consumo humano e se padrão de potabilidade. Diário Oficial da União, Brasília, DF, 12 dez. 2011. Seção 1, p. 39.

BRASIL. Ministério da Saúde. Portaria de Consolidação Nº 5, de 28 de setembro de 2017. Estabelece a consolidação das normas sobre as ações e os serviços de saúde do Sistema Único de Saúde.

MELO, C. M. R. As atividades lúdicas são fundamentais para subsidiar ao processo de construção do conhecimento. Información Filosófica, v. 2, n. 1, p. 128-137, 2005.

MIRANDA, S. No fascínio do jogo, a alegria de aprender. Ciência Hoje, v. 28, p. 64-66, 2001.

PARREIRA et al. Desenvolvimento de Jogos Educacionais Digitais: algumas experiências do Grupo de Pesquisa IATE/UFSM - Inteligência Artificial e Tecnologia Educacional. Anais do EATI, ano 6, n. 1, p. 116-123. 2016.

TUNDISI, J.G. et al. Recursos hídricos no Brasil: problemas, desafios e estratégias para o futuro. Rio de Janeiro: Academia Brasileira de Ciências, 2014. 